University of Nebraska - Lincoln

DigitalCommons@University of Nebraska - Lincoln

USDA Wildlife Services - Staff Publications

U.S. Department of Agriculture: Animal and Plant Health Inspection Service

2011

The Nebraska Deer Exchange: A Novel Program for Donating Harvested Deer

Aaron M. Hildreth

University of Nebraska-Lincoln, hildreta@gmail.com

Scott Hygnstrom

University of Nebraska-Lincoln, shygnstrom1@unl.edu

Kit M. Hams

Nebraska Game and Parks Commission

Kurt C. Vercauteren

USDA-APHIS-Wildlife Services, kurt.c.vercauteren@usda.gov

Follow this and additional works at: https://digitalcommons.unl.edu/icwdm_usdanwrc

Hildreth, Aaron M.; Hygnstrom, Scott; Hams, Kit M.; and Vercauteren, Kurt C., "The Nebraska Deer Exchange: A Novel Program for Donating Harvested Deer" (2011). USDA Wildlife Services - Staff Publications. 1360.

https://digitalcommons.unl.edu/icwdm_usdanwrc/1360

This Article is brought to you for free and open access by the U.S. Department of Agriculture: Animal and Plant Health Inspection Service at DigitalCommons@University of Nebraska - Lincoln. It has been accepted for inclusion in USDA Wildlife Services - Staff Publications by an authorized administrator of DigitalCommons@University of Nebraska - Lincoln. 


\title{
The Nebraska Deer Exchange: A Novel Program for Donating Harvested Deer
}

\author{
AARON M. HILDRETH, ${ }^{1,2}$ School of Natural Resources, University of Nebraska, 3310 Holdrege Street, Lincoln, NE 68583, USA \\ SCOTT E. HYGNSTROM, School of Natural Resources, University of Nebraska, 3310 Holdrege Street, Lincoln, NE 68583, USA \\ KIT M. HAMS, Nebraska Game and Parks Commission, 2200 N 33rd Street, Lincoln, NE 68503, USA \\ KURT C. VERCAUTEREN, United States Department of Agriculture, Animal and Plant Health Inspection Service, Wildlife Services, \\ National Wildlife Research Center, 4101 LaPorte Avenue, Fort Collins, CO 80521, USA
}

\begin{abstract}
Populations of white-tailed deer (Odocoileus virginianus) have become overabundant throughout their historic range, especially in developed landscapes. A variety of techniques, including controlled hunts in urban-suburban areas, are being used to increase harvest. Deer donation programs have been initiated in nearly all 50 states of the United States, and have been successful at providing venison to the hungry, but at significant costs to wildlife agencies and hunters. Our objectives were to: 1) develop a low-cost program to facilitate the exchange of excess harvested deer from hunters to recipients; 2) evaluate the attitudes of participating hunters and recipients; and 3) determine the effectiveness of the Nebraska Deer Exchange (NDE). The NDE was developed in 2008, featuring an interactive webpage hosted by the Nebraska Game and Parks Commission (NGPC). The NDE served as a database and matchmaker for hunters and recipients to contact each other and arrange the transfer of harvested deer. We evaluated the program by conducting an e-mail survey of participants. The code and website for the NDE were developed in $40 \mathrm{hr}$ and the overall cost to NGPC was US\$1,120. A total of 1,172 people participated the first year and $>6,900 \mathrm{~kg}$ of venison was donated to willing recipients. Sixty-six percent of donors indicated they harvested additional deer as a direct result of the NDE. Surveyed participants overwhelmingly indicated that the program was easy, inexpensive, and should continue the next year. The NDE aided in the harvest of additional deer, increased interactions between hunters and nonhunters, and provided nutritious venison to willing recipients. (C) 2011 The Wildlife Society.
\end{abstract}

KEY WORDS developed landscapes, donation, human dimensions, hunter, hunting, Nebraska, Odocoileus virginianus, venison, white-tailed deer.

Since the end of market hunting and the inception of modern wildlife management, white-tailed deer (Odocoileus virginianus) have increased in numbers and expanded their range in North America (Brown et al. 2000, Côté et al. 2004). Many state wildlife agencies are currently struggling to reduce densities of deer to population goals in rural areas and developed landscapes, while contending with limited hunter access, anti-hunting sentiment, and balancing nonconsumptive uses of deer (Decker and Chase 1997, DeNicola et al. 1997, Brown et al. 2000). The use of hunting has been the most cost-effective method of managing deer populations (Palmer et al. 1980, DeNicola et al. 1997, Doerr et al. 2001) in both rural and developed landscapes (Craven and Hygnstrom 1994, DeNicola et al. 2000). State agencies are increasing the number of bonus tags and antlerless-only permits to increase harvest and decrease numbers of deer

Received: 21 September 2010; Accepted: 14 February 2011

${ }^{1}$ E-mail: hildreta@gmail.com

${ }^{2}$ Present address: United States Department of Agriculture, Animal and Plant Health Inspection Service, Wildlife Services, National Wildlife Research Center, 4101 LaPorte Avenue, Fort Collins, CO 80521.
(Witmer and DeCalesta 1991, Brown et al. 2000, Van Deelen et al. 2010). The number of hunters often is limited in controlled hunts in developed landscapes because of space limitations and safety concerns (Hubbard and Nielsen 2011), so to increase harvest, managers must increase the number of permits available (Hansen and Beringer 1997, Kilpatrick and Lima 1999, Kilpatrick et al. 2002). Even with increases in permits, success in lowering deer numbers has been limited (Côté et al. 2004). Hunters may not have the need for bonus tags or a willingness to pay for extra tags. Sometimes hunters choose not to harvest additional deer because of a desire to maintain or increase current densities of deer, lack of motivation to harvest more deer than they can use themselves, lack of a convenient method by which to donate excess deer, and financial constraints (Miller and Vaske 2003, Côté et al. 2004, Holsman and Petchenik 2006). Agencies may find it difficult to address the first 2 issues, but they can provide hunters with deer permits at reduced costs and a convenient, low-cost method to donate excess meat.

The diminishing returns associated with providing hunters with more opportunities to harvest animals are documented (Van Deelen and Etter 2003, Giles and Findlay 2004) and 
have caused some researchers to explore incentive-based methods of increasing harvest (Brown et al. 2000, Giles and Findlay 2004, Stedman et al. 2004). Donation programs can serve as an additional incentive for hunters to harvest more deer (Van Deelen et al. 2010).

Deer donation programs exist in nearly all 50 states and a few have been successful in facilitating the donation of thousands of deer each year (Wisconsin Department of Natural Resources 2009; Iowa Department of Natural Resources 2010a,b). Unfortunately, these programs have come at a great expense to state wildlife agencies and hunters, or been heavily subsidized by private monetary contributions (Prouty 2007; Wisconsin Department of Natural Resources 2009; Iowa Department of Natural Resources 2010a,b). The objectives of this project were to: 1) develop a low-cost program in Nebraska to facilitate the exchange of excess harvested deer from hunters to recipients; 2) evaluate the attitudes of participating hunters and recipients; and 3) determine the effectiveness of the program.

\section{STUDY AREA}

Our study area was the state of Nebraska, located in the Great Plains of the United States. Nebraska has a variable climate characterized as subhumid in the east and semiarid in the west with an east-to-west increase in elevation and decrease in precipitation and mean temperature (Wilhelmi and Wilhite 2002). Agricultural crops and deciduous forest dominated the eastern third of the state, with agricultural crops and short-mixed-grass prairies increasing in dominance from east to west. Three eastern counties (Douglas, Lancaster, and Sarpy) contained $52.6 \%$ of the human population in Nebraska (U.S. Census Bureau 2010). Human population densities decreased from east to west for the remainder of the state.

White-tailed deer were found statewide, but occurred in the greatest densities (sometimes exceeding $25 / \mathrm{km}^{2}$ ) in the eastern half of the state and along major river corridors including the Missouri, Platte, and Republican Rivers. The state was divided into 18 Deer Management Units for the 9-day either-sex firearm season and 26 Season Choice Units for antlerless harvest during archery, firearm, and muzzleloader seasons. Sixty percent or more of the state's deer harvest occurred during the 9-day firearm season. Despite record or near-record harvests, increases in permit availability, and an increase in antlerless harvest, the population of white-tailed deer is continuing to increase in both rural and developed landscapes across the state (K. Hams, Nebraska Game and Parks Commission, unpublished work).

\section{METHODS}

\section{Program Description and Design}

The "Nebraska Deer Exchange" (NDE; http://outdoornebraska.ne.gov/hunting/programs/deerexchange/) was developed by the authors to provide hunters who harvest more deer than they personally can use with an easy and inexpensive method for donating deer to individuals or organizations for consumption. We used the NGPC website to host the program. The website included sign-up information; an explanation of the program and its benefits; a downloadable custody tag; information about lead in wild game meat; how to care for and process a deer; and lists of processors, recipes, and frequently asked questions.

Participants signed up for the program on the NGPC website. The program was available from mid-October 2008 through mid-January 2009. All participants were required to provide their first and last name, address, and phone number. E-mail addresses were optional. Participants indicated whether they wished to donate or receive a deer, the condition of meat desired (field-dressed, skinned, quartered, boned, ground, packaged, or jerky-sausage) and the quantity of meat desired. Participants were sorted by county and classified as donors or recipients. Participants could search by county to locate people in their region of the state. Donors and recipients could initiate contact to arrange delivery and processing of deer. No costs were required to participate and the deer meat could not be sold. The donor was responsible for following all laws and regulations regarding the harvest and transfer of deer including possessing a valid permit and obtaining a custody tag to transfer custody of the deer to a recipient.

\section{Survey Design}

We surveyed all participants who provided an e-mail address, to assess attitudes of participants and to determine the effectiveness of the NDE. We used SurveyMonkey ${ }^{\mathrm{TM}}$ to conduct the e-mail survey. We sent the survey out 3 times using a variation of the repeated mailing technique of Dillman (1978) during May 2009. We asked donating participants 18 questions, and receiving participants 21 questions, regarding ease of use, expense, success, and privacy associated with the NDE.

We randomly surveyed $10 \%$ of participants who provided a telephone number by phone to assess whether there was any nonresponse bias from the e-mail survey (Horton and Craven 1997, Braithwaite et al. 2003). We used 2 sample $t$-tests assuming equal variances and $95 \%$ confidence intervals $(\alpha=0.05)$ to determine whether any differences existed between the phone and e-mail survey groups. We asked the same 18 questions to donors and 21 questions to recipients who were used in the e-mail survey. Thirty-three donors and 46 recipients from the list (no. needed for $10 \%$ sample) were called twice unless they responded to the first call. New participants were added to the initial 33 and 46 when 2 call attempts failed. E-mail addresses that were invalid were removed from the count and calculation of the total surveyed population, because they never had an opportunity to complete the survey. The surveys were approved by the University of Nebraska-Lincoln Institutional Review Board (no. 2009049876EP).

We evaluated the effectiveness of the NDE at increasing deer harvest using questions from our e-mail survey. We asked donors how many deer they donated and whether they harvested additional deer as a result of the program. We asked recipients whether they would go hunting to get a deer of their own and whether they had a deer permit during the 
2008 hunting season. We also evaluated what type of deer meat was donated, how the deer were transferred from the donor to the recipient, how participants contacted each other, and how participants discovered the program.

\section{RESULTS}

We spent $26 \mathrm{hr}$ (at US\$15/hr) during 4 meetings designing the NDE. An information technology (IT) specialist spent $40 \mathrm{hr}$ (at US $\$ 25 / \mathrm{hr}$ ) designing the web-based portion of the program and making it available to the public. Twenty-five hours were spent designing the e-mail surveys, $45 \mathrm{hr}$ conducting the phone survey, and $40 \mathrm{hr}$ analyzing and interpreting the results (all at US $\$ 11 / \mathrm{hr}$ ). The initial start-up cost totaled US $\$ 2,600$. The total cost to the NGPC was US $\$ 1,120$ and the remainder was paid for by the University of Nebraska-Lincoln. The IT specialist estimated it would take $<5 \mathrm{hr}$ /year to update the site after the initial year $(<$ US\$125/yr).

A total of 1,172 people participated in the NDE in 2008. Donors comprised $40 \%$ of participants and recipients made up the remaining $60 \%$. Thirty-seven percent of participants were from Douglas, Lancaster, and Sarpy counties (the 3 most populous counties in NE). Thirty-five percent of participants were located in the eastern third of the state (not including Douglas, Lancaster, and Sarpy counties), and the remaining $28 \%$ were in the western two-thirds of the state. The NDE facilitated the exchange of 298 deer in 2008. The initial cost to the NGPC of US $\$ 1,120$ equals US $\$ 3.76$ / deer donated. The cost per deer would decrease to US $\$ 0.42 /$ deer if we assume the maximum estimated cost for maintenance of the website in subsequent years (US\$125/yr) and no increase in the number of donated deer.

Three hundred twenty-four of 632 (51.3\%) participants responded to the e-mail survey (217 donor responses and 415 recipients). Donor response rate was $53.0 \%(n=115)$ and recipient response rate was $50.4 \%(n=209)$ for the e-mail survey. Contact information for 23 donors and 40 recipients was invalid or undeliverable. Fourteen participants opted out of answering the e-mail survey.

Comparisons between e-mail and phone survey groups revealed no nonresponse bias in participant attitudes regardless of whether or not donors were successful in donating a deer or recipients were successful in receiving a deer (Donor $t=-1.85, P \geq 0.11 ;$ Recipient $t=-1.87, P \geq 0.11)$. Therefore, we used the e-mail survey to analyze the NDE. E-mail survey respondents, however, were twice as likely to donate or receive a deer compared to phone survey respondents.

Sixty-six percent of donors indicated they harvested additional deer as a direct result of the NDE. Seventy-seven percent of recipients said they would go hunting to get their deer, but only $27 \%$ had a deer permit in 2008 . Sixty-eight percent of deer transferred to recipients were field-dressed and $50 \%$ were delivered to recipients by the donors. The NGPC website was the most cited method (51.6\%) participants used to find out about the program. Other methods included friends (23.0\%), media (13.6\%), and other (11.7\%). Individual recipients spent an average of US $\$ 15 /$ deer
Table 1. E-mail survey responses of participants in the Nebraska Deer Exchange program in Nebraska, USA, 2008.

\begin{tabular}{lcccc}
\hline Question & Donors & SD & Recipients & SD \\
\hline Easy & $3.71^{\mathrm{a}}$ & 0.49 & 3.66 & 0.78 \\
Inexpensive & 3.63 & 0.62 & 3.81 & 0.46 \\
Appreciative & 3.83 & 0.44 & 3.78 & 0.71 \\
Improve relations & 3.27 & 0.59 & 3.47 & 0.64 \\
Continue next yr & 3.77 & 0.42 & 3.83 & 0.40 \\
Participate next yr & 3.71 & 0.64 & 3.72 & 0.57 \\
Did not violate privacy & 3.65 & 0.66 & 3.61 & 0.74 \\
\hline
\end{tabular}

${ }^{\mathrm{a}}$ Values near 1 = strongly disagree; values near $4=$ strongly agree.

(range $=$ US $\$ 0-\$ 300 /$ deer) on processing. Recipients were $32 \%$ more likely to contact donors inquiring about a deer and to tell others about the program than donors.

After extrapolating data from the e-mail survey, we estimated that 188 (40\%) donors donated $\geq 1$ deer and 182 (25.9\%) recipients received $\geq 1$ deer. Donors and recipients of deer expressed high levels of satisfaction with the NDE regarding the ease of use, lack of expense, and respect for privacy (Table 1). Both groups were highly appreciative of the program, encouraged that it continues in the future, and indicated they would participate in the future (Table 1). Comments revealed 2 areas needing improvement: advertising and clarity of instructions for the program.

\section{DISCUSSION}

We were successful in developing a convenient, low-cost program to facilitate the exchange of deer from hunters to willing recipients. Most donors (66\%) stated that they harvested additional deer because of the NDE and $37 \%$ of the participants were from highly developed landscapes near the cities of Lincoln and Omaha, Nebraska. Several controlled hunts have occurred in developed landscapes with the intent of reducing the density of deer through hunter harvest (McAninch 1993, Kuser 1995, Kilpatrick and Walter 1999, Kilpatrick et al. 2002, VerCauteren and Hygnstrom 2002). Often the number of hunters that can participate in controlled hunts is limited because of the limited space and proximity to residential areas and other human-inhabited property (Hansen and Beringer 1997, Kilpatrick and Lima 1999, Kilpatrick et al. 2002). Thus, it would be useful if such hunters could harvest more deer than what would typically satiate their hunting interests for the collection of venison for their own personal use. The NDE program could be linked to controlled hunts in developed landscapes to facilitate the increased harvest of deer in urban-suburban areas.

The 298 donated deer translated into $>6,900 \mathrm{~kg}$ of venison, assuming $23.3 \mathrm{~kg}$ of useable meat per deer (uses fielddressed wt of $41.4 \mathrm{~kg} /$ deer [T. Hefley, University of Nebraska-Lincoln, personal communication; Ask The Meatman 2009]). The market value of the donated deer meat is around US\$59,300 when compared to the June 2010 nationwide average price for $90 \%$ lean ground beef (U.S. Department of Agriculture 2010). The market value of each deer is around US $\$ 199$, assuming $23.3 \mathrm{~kg}$ of meat per deer and using the June 2010 nationwide average price for ground beef. The cost of the NDE is essentially fixed because only $5 \mathrm{hr} /$ year are required to maintain the website. 
Consequently, as the number of donated deer increases, the cost per deer to NGPC goes down. With other venison donation programs that pay per deer, as the number of donated deer increases so does the cost.

The current trend with deer donation programs places the majority of the financial responsibility on hunters and state agencies (Prouty 2007; New Jersey Division of Fish and Wildlife 2009; Wisconsin Department of Natural Resources 2009; Iowa Department of Natural Resources 2010b). Programs like Iowa's Help Us Stop Hunger (HUSH) and Wisconsin's statewide deer-donation program have been successful at getting hunters to donate harvested deer, but have done so at considerable expense to the agencies and hunters (Prouty 2007; Wisconsin Department of Natural Resources 2009; Iowa Department of Natural Resources $2010 a$ ). In 7 years, Iowa spent nearly US $\$ 2.8$ million on HUSH and overspent their allotted funds by US $\$ 655,000$ (Iowa Department of Natural Resources $2010 a$ ). The US $\$ 655,000$ Iowa overspent translates into a cost of US $\$ 17.07$ per donated deer (4.5 times more expensive/deer than the initial yr of the NDE). Wisconsin spent US\$205,000 in 2009 (Koele 2009) and Illinois spent US $\$ 100,000$ annually (Illinois Department of Natural Resources 2008) on their statewide deer-donation programs. New Jersey hunters must contribute US $\$ 25-\$ 65$ per donated deer since the state is no longer able to support their deer donation program due to high costs. Connecticut, Georgia, Minnesota, Missouri, Pennsylvania, Tennessee, and Texas require hunters to pay for processing deer that are donated unless butchers or other organizations donate their time or money to cover costs associated with processing (Prouty 2007).

Some states offer free processing or rebates when entire deer are donated (Prouty 2007). Farmers and Hunters Feeding the Hungry (FHFH) is the largest deer donation program in the nation with 124 chapters operating in 26 states (FHFH 2007). Farmers and hunters who donate an entire deer pay nothing and the processing costs are covered by monetary donations from churches, clubs, businesses, and individuals to the program (FHFH 2007). All meat donated through FHFH is given to local food banks free of charge to be distributed to the needy in associated communities. Through the process, no personal interaction occurs between donors and recipients. The lack of interaction inhibits the building of friendships that could lead to self-sustaining donation processes. The current process also precludes people who would like to receive meat and pay for processing.

Participants in the NDE had to contact each other and arrange details for the transfer of harvested deer. An evaluation of the attitudes of participants revealed overwhelming satisfaction with the program. Improved advertising and clarity of instructions for the program were cited as those areas most in need of improvement. Participants thought more media coverage and flyer-type advertising would help make the program more widely known and increase participation. Many recipients mistakenly thought NGPC would notify them of a donor in their area with a deer to exchange and many donors thought the recipients would contact them asking about a deer. The NDE was designed to allow participants to contact each other and minimize agency involvement. Information about how donors and recipients could contact each other and how to search for participants by county was posted on the website, but suggestions were made on how to make that information more visible.

We noticed that e-mail survey respondents were twice as likely to have donated or received a deer compared to telephone survey respondents. Despite the difference in the number of deer donated or received, the participants' attitudes remained the same.

Most donors (66\%) said they harvested additional deer as a direct result of the program. The number of additional deer harvested should increase as the NDE continues to grow in the future. Despite only $27 \%$ of recipients possessing a deer permit in $2008,77 \%$ of all recipients said they would go hunting to get a deer of their own. Recipients who possessed a deer permit most often cited a desire to receive more deer and an inability to hunt (injury, family incident) as reasons they joined the recipient list. Any concern about decreased or stable harvest as a result of hunter retention-recruitment loss due to the availability of deer through the NDE seems to be of little worry because $92 \%$ of hunters indicated a desire to participate next year and $66 \%$ of donors said they harvested additional deer as a direct result of the NDE. With $>5,000$ antlerless-only permits unsold at the conclusion of the 2008 deer season, and an unlimited number of archery and muzzleloader permits available, recipients could have purchased deer hunting permits (K. Hams, unpublished work). Hunters who already have access and knowledge about hunting could serve as mentors to others interested in hunting and harvesting their own deer. The continued decline of hunters over the past few decades has led to a growing concern about the ability of hunters to control growing populations of whitetailed deer and fund state wildlife agencies (Brown et al. 2000, Riley et al. 2003, VerCauteren and Hygnstrom 2011). Programs designed to recruit, develop, and retain new generations of hunters are forming within state agencies to reverse the trend of declining hunter numbers. Programs like the NDE will continue to cast a good light on hunters, provide opportunities for hunters and nonhunters to interact, and may facilitate hunter recruitment.

More than $99 \%$ of registered recipients were individuals and donors indicated that only $3 \%$ of recipients of deer represented organizations such as food banks and city missions. These institutions comprise the majority of recipients in most other states with deer donation programs (FHFH 2007; Illinois Department of Natural Resources 2008; New Jersey Division of Fish and Wildlife 2009; Wisconsin Department of Natural Resources 2009; Iowa Department of Natural Resources 2010b). Demand for deer through the NDE could be increased considerably if organizations were more engaged. Increased networking and recruitment of organizations as recipients likely would increase the number of deer desired and donated. Food banks and city missions, however, rely on processed venison for their clientele, which could put the burden of cost back on the donors or wildlife agencies. 
Costs for processing deer are about US $\$ 100 /$ deer if it is only skinned, boned, ground, and packaged and can be up to US $\$ 300 /$ deer if specialty cuts and sausage-jerky are made (estimates from local processors). Although the majority of hunters were unable or unwilling to cover the costs of processing for donated deer, some indicated they would cover the cost.

Most (68\%) of the deer donated through the NDE program were just field-dressed. Field-dressed deer are the easiest to provide from a donor perspective and $<1 \%$ of recipients complained about receiving deer in that condition.

The custody tag required to transfer custody of the deer from donor to recipient was available on the NDE website as a pdf users could easily open and print. The custody tag existed prior to the start of the NDE and has been approved by the NGPC Division of Law Enforcement.

The NDE provides a solution for high hunter and state agency cost and the lack of personal interaction between donor and recipient. Unlike other donation programs managed by state agencies, the cost to the NGPC included only minor administrative costs associated with program design, set-up, and promotion. The costs to the hunter were how much they wanted to pay, ranging from the cost of their permit and all of the processing to having the recipient pay for all processing and, in some instances, their permit.

We feel the inaugural year of the NDE was a success. Additional deer were harvested in the state and participants were very satisfied with the program. We plan to improve the program in the future and offer it to other state agencies to use as a tool to increase deer harvest in rural and developed landscapes, deer donations, and public relations, and decrease hunter and agency costs associated with deer donation programs.

\section{MANAGEMENT IMPLICATIONS}

The adoption of similar deer donation programs by other states would provide easy, low-cost programs to encourage the harvest of additional deer. Programs like the NDE also provide deer meat to those who want or need nutritious venison, but are unable or unwilling to hunt. State agency involvement, and ultimately cost, are minimized, allowing allocation of funds to other projects and programs because exchanges are between 2 private parties. The positive public attention toward state game agencies and hunters from the program would help reinforce the utility of hunting as a tool of sound wildlife management.

Deer donation programs also serve as an added incentive for hunters to harvest more deer. The ability to donate additional deer may incite hunters to harvest more deer because they will be used and may require little effort or money from the hunter. Programs such as the NDE could be linked with controlled hunts in developed landscapes across the nation to increase harvest and decrease densities of deer in urban-suburban areas.

\section{ACKNOWLEDGMENTS}

We thank J. Hoffman and T. Kroeger of the NGPC for their assistance in developing the program. Funding was provided by the NGPC and the University of Nebraska-Lincoln School of Natural Resources. Thank you to the donors and recipients who responded to our survey.

\section{LITERATURE CITED}

Ask The Meatman. 2009. Estimate deer weight. < http://www.askthemeatman. com/estimate_deer_weight.htm >. Accessed 11 Feb 2011.

Braithwaite, D., J. Emery, S. de Lusignan, and S. Sutton. 2003. Using the Internet to conduct surveys of health professionals: a valid alternative? Family Practice 20:545-551.

Brown, T. L., D. J. Decker, S. J. Riley, J. W. Enck, T. B. Lauber, P. D. Curtis, and G. F. Mattfeld. 2000. The future of hunting as a mechanism to control white-tailed deer populations. Wildlife Society Bulletin 28:797807.

Côté, S. D., T. P. Rooney, J. Tremblay, C. Dussault, and D. M. Waller. 2004. Ecological impacts of deer overabundance. Annual Review of Ecology, Evolution, and Systematics 35:113-147.

Craven, S. R., and S. E. Hygnstrom. 1994. Pages D25-D40 in S. E. Hygnstrom, R. M. Timm, and G. E. Larson, editors. Prevention and control of wildlife damage. University of Nebraska Cooperative Extension, Lincoln, USA.

Decker, D. J., and L. C. Chase. 1997. Human dimensions of living with wildlife: a management challenge for the 21st century. Wildlife Society Bulletin 25:788-795.

DeNicola, A. J., K. C. VerCauteren, P. D. Curtis, and S. E. Hygnstrom. 2000. Managing white-tailed deer in suburban environments. Cornell University Cooperative Extension, Ithaca, New York, USA.

DeNicola, A. J., S. J. Weber, C. A. Bridges, and J. L. Stokes. 1997. Nontraditional techniques for management of overabundant deer populations. Wildlife Society Bulletin 25:496-499.

Dillman, D. A. 1978. Mail and telephone surveys: the total design method. Wiley, New York, New York, USA.

Doerr, M. L., J. B. McAninch, and E. P. Wiggers. 2001. Comparison of 4 methods to reduce white-tailed deer abundance in an urban community. Wildlife Society Bulletin 29:1105-1113.

Farmers and Hunters Feeding the Hungry [FHFH]. 2007. About FHFH. <http://www.fhfh.org/About.asp>. Accessed 23 Jun 2010.

Giles, B. G., and C. S. Findlay. 2004. Effectiveness of a selective harvest system in regulating deer populations in Ontario. Journal of Wildlife Management 68:266-277.

Hansen, L., and J. Beringer. 1997. Managed hunts to control white-tailed deer populations on urban public areas in Missouri. Wildlife Society Bulletin 25:484-487.

Holsman, R. H., and J. Petchenik. 2006. Predicting deer hunter harvest behavior in Wisconsin's chronic wasting disease eradication zone. Human Dimensions of Wildlife 11:177-189.

Horton, R. R., and S. R. Craven. 1997. Perceptions of shooting-permit use for deer damage abatement in Wisconsin. Wildlife Society Bulletin 25:330-336

Hubbard, R. D., and C. K. Nielsen. 2011. Cost-benefit analysis of managed shotgun hunts for suburban white-tailed deer. Human-Wildlife Interactions 5:13-22.

Illinois Department of Natural Resources. 2008. Deer hunters encouraged to donate to the Illinois Sportsmen Against Hunger Program. <http:// dnr.state.il.us/pubaffairs/2008/October/ISAH.html $>$. Accessed 16 Feb 2010.

Iowa Department of Natural Resources. 2010a. Iowa donated deer. < http:// www.iowadnr.gov/other/hush/files/hush_history.pdf $>$. Accessed 23 Jun 2010.

Iowa Department of Natural Resources. 2010b. HUSH: Help us Stop Hunger. <http://www.iowadnr.gov/other/hush/>. Accessed 25 Jan 2011.

Kilpatrick, H. J., A. M. LaBonte, and J. T. Seymour. 2002. A shotgunarchery deer hunt in a residential community: evaluation of hunt strategies and effectiveness. Wildlife Society Bulletin 30:478-486.

Kilpatrick, H. J., and K. K. Lima. 1999. Effects of archery hunting on movement and activity of female white-tailed deer in an urban landscape. Wildlife Society Bulletin 27:433-440.

Kilpatrick, H. J., and W. D. Walter. 1999. A controlled archery deer hunt in a residential community: cost, effectiveness, and recovery rates. Wildlife Society Bulletin 27:115-123. 
Koele, B. 2009. Wildlife Damage Abatement and Claims Program, 2009. $<$ http://www.dnr.state.wi.us/org/land/wildlife/damage/progreport.pdf $>$. Accessed 23 Jun 2010.

Kuser, J. 1995. Deer and people in Princeton, New Jersey, 1971-1993. Pages 58-65 in J. B. McAninch, editor. Urban deer: a manageable resource? Proceedings of the Symposium of the North Central Section, The Wildlife Society, 12-14 December 1993, St. Louis, Missouri, USA.

McAninch, J. B. 1993. Use of bowhunting in deer population management programs in Minnesota. Pages 33-36 in D. E. Guynn and D. E. Samuel, editors. Proceedings of the Western Bowhunting Conference, 21-23 May 1993, Bozeman, Montana, USA.

Miller, C. A., and J. J. Vaske. 2003. Individual and situational influences on declining hunter effort in Illinois. Human Dimensions of Wildlife 8:263276.

New Jersey Division of Fish and Wildlife. 2009. Hunters helping the hungry. $<$ http://www.state.nj.us/dep/fgw/hlphngry.htm $>$. Accessed 23 Jun 2010.

Palmer, D. T., D. A. Andrews, R. O. Winters, and J. W. Francis. 1980. Removal techniques to control an enclosed deer herd. Wildlife Society Bulletin 8:29-33.

Prouty, D. C. 2007. Help Us Stop Hunger Program. <http://www.legis. state.ia.us//sadocs/IssReview/2008/IRDFK001.PDF > . Accessed 23 Jun 2010.

Riley, S. J., D. J. Decker, J. W. Enck, P. D. Curtis, and B. Lauber. 2003. Deer populations up, hunter populations down: implications of interdependence of deer and hunter population dynamics on management. Ecoscience 10:455-461.

Stedman, R., D. R. Diefenbach, C. B. Swope, J. C. Finley, A. E. Luloff, H. C. Zinn, G. J. San Julian, and G. A. Wang. 2004. Integrating wildlife and human dimensions research methods to study hunters. Journal of Wildlife Management 68:762-773.
U.S. Census Bureau. 2010. State and county quick facts: Nebraska. <http:// quickfacts.census.gov/qfd/states/31000.html>. Accessed 24 Jan 2011.

U.S. Department of Agriculture. 2010. USDA weekly retail beef feature activity. $<$ http://search.ams.usda.gov/mndms/2010/06/LS20100618WBFRTL. PDF $>$. Accessed $11 \mathrm{Feb} 2011$.

Van Deelen, T. R., B. J. Dhuey, C. N. Jacques, K. R. McCaffery, R. E. Rolley, and K. Warnke. 2010. Effects of earn-a-buck and special antlerless-only seasons on Wisconsin's deer harvests. Journal of Wildlife Management 74:1693-1700.

Van Deelen, T. R., and D. R. Etter. 2003. Effort and the functional response of deer hunters. Human Dimensions of Wildlife 8:97-109.

VerCauteren, K. C., and S. E. Hygnstrom. 2002. Efficacy of hunting for managing a suburban deer population in eastern Nebraska. Proceeding of the National Bowhunting Conference 1:51-58.

VerCauteren, K. C., and S. E. Hygnstrom. 2011. Managing white-tailed deer: Midwest North America. Pages 501-535 in D. Hewitt, editor. Biology and management of white-tailed deer. Taylor and Francis, Boca Raton, Florida, USA.

Wilhelmi, O. V., and D. A. Wilhite. 2002. Assessing vulnerability to agricultural drought: a Nebraska case study. Natural Hazards 25: $37-58$.

Wisconsin Department of Natural Resources. 2009. Wildlife Damage Abatement and Claims Program information. <http://www.dnr.state. wi.us/org/land/wildlife/damage/proginfo.htm>. Accessed 23 Jun 2010.

Witmer, G. W., and D. S. DeCalesta. 1991. The need and difficulty of bringing the Pennsylvania deer herd under control. Eastern Wildlife Damage Control Conference 5:130-137.

Associate Editor: Nielsen. 